\title{
PROTOTYPE PENERANGAN LAMPU TAMAN OTOMATIS MENGGUNAKAN ARDUINO UNO
}

\author{
Mugi Alan Prasetya ${ }^{1}$, Rachmat Aulia $^{2}$
}

\author{
${ }^{1,2}$ Program Studi Teknik Informatika Universitas Teknik Harapan Medan \\ Jl. HM. Joni, No.70 Medan \\ ${ }^{1}$ wilanmugi@gmail.com, ${ }^{2}$ jackm4t@gmail.com
}

\begin{abstract}
Abstrak - Masalah yang sering dihadapi pada pekerja di fasilitas umum contohnya pada lampu taman adalah harus menghidupkan dan mematikan lampu taman secara manual dan ditambah lagi arus listrik yang digunakan dirasa boros karena harus menunggu petugas dalam menghidupkan dan mematikan lampu, maka dari itu perlu dibuatnya sistem otomatis yang dapat membantu dan memberikan solusi pada permasalahan tersebut, maka dari itu penulis membuat sistem lampu taman otomatis dengan menggunakan sensor ldr yang dapat digunakan untuk membaca nilai kondisi cuaca (terang atau gelap). Sensor ultrasonik berguna untuk mendeteksi pergerakan dengan membaca jarak yang telah ditentukan. Relay yang dapat digunakan sebagai kontaktor arus yang masuk ke lampu. Dimana sistem yang dibuat nantinya membutuhkan power supply dari tegangan adaptor. Dalam penelitian ini dapat disimpulkan bahwa dengan menggunakan sensor cahaya dapat digunakan sebagai pendeteksian kondisi hari(siang atau malam) dan dengan bantuan sensor ultrasonik sebagai nilai inputan untuk menghidupkan atau mematikan lampu (seperti animasi) dengan tujuan untuk menghemat arus listrik yang digunakan. Yang mana nantinya lampu akan hidup dan mati sesuai dengan nilai sensor ultrasonik ketika ultrasonik 1 mendeteksi objek maka lampu akan akan hidup dan yang lainnya padam, dan ketika sudah tidak mendeteksi objek lagi maka lampu akan padam, begitu selanjutnya sampai ke ultrasonic 4 dan lampu akan hidup dan mati (seperti animasi) sesuai dengan nilai ultrasonik..
\end{abstract}

Kata kunci-Sensor Ldr, Sensor Ultrasonik, dan Relay

Abstract- The problem which often faced by employee public facilities such as garden lamp is have to turn on and turn off the garden lamp in manual way and than the circuit that used is overprice because the employees need to wait the staff of park to turn on and turn off the lamp, because of that automatic system needed for help and solve the problem. In addition, the researcher decide to create a garden lamp with automatic system by using LDR sensor which used to sensor the condition of the weather (light or dark). The ultrasonic sensor can be used to monitor the situation through the predetermined distance. Relay can be used as current contactor into the lamp. The system will be need a power supply from the adaptor voltage.

Keywords-LDR sensor, Ultrasonic sensor, and Relay.

\section{PENDAHULUAN}

Taman merupakan tempat rekreasi keluarga yang dilihat dari keindahannya, yang didukung dengan material yang mendukung satu sama lain, misalnya dalam bidang pencahayaan, keindahan pepohonan, dan material pendukung lainnya, Seperti yang kita tau, taman tidak hanya tempat bermainnya saja yang dapat dinikmati melainkan hiasan pencahayaan lampu yang disusun untuk mendukung keindahan dari taman tersebut.

Berdasarkan Instruksi Presiden Republik Indonesia Nomor 10 Tahun 2005 tentang penghematan energi, maka diharapkan setiap masyarakat pemakai listrik dapat menghemat penggunaan energy listrik di rumah atau pun tempat kerja masing-masing. Alasan inilah perlu dirancang sebuah sistem kontrol otomatis untuk perangkat elektronik untuk penghematan energy listrik.[1]
Untuk menyelesaikan persoalan diatas, kita membutuhkan sistem alat yang dapat memanipulasi lampu secara otomatis yang bersifat terurut dengan menggunakan mikrokontroler sebagai pengendaliannya.[2]

\section{METODE}

A. Mikrocontroler

Sebuah mikrocontroler telah berisi semua komponen yang memungkinkannya beroperasi mandiri, dan telah dirancang secara khusus untuk tugas monitoring atau kontrol.[3]

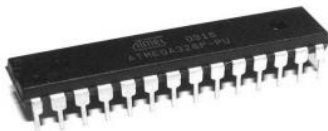

Gbr 1 Atmega 328 


\section{B. Arduino}

Arduino merupakan rangkaian elektronika yang bersifat open source, serta memiliki perangkat keras dan lunak yang mudah untuk digunakan. [4]

Page | 110

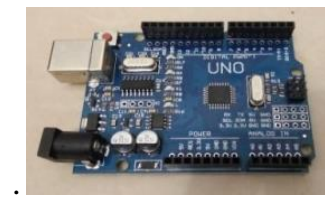

Gbr 2 Arduino UNO

\section{Software Arduino IDE}

Tahap ini merupakan proses membangun simulasi sistem pengendalian yang sebelumnya, dan juga dan juga dilakukan kegiatan pengaturan pin pada mikrokontroler untuk membuat sistem pengendalian. Pemrograman mikokontroler Arduino Uno ini menggunakan software Arduino IDE sketch.

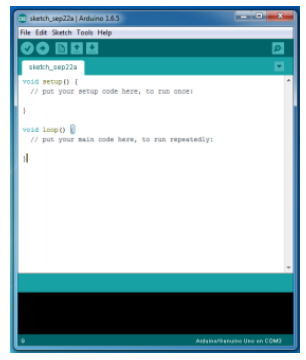

Gbr 3 Software Arduino IDE

\section{LDR (Light Dependent Resistor)}

LDR atau light Dependent Resistor adalah salah satu jenis sensor yang pembacaan nilainya berdasarkan oleh keterangan cahaya yang diterima olehnya. Besarnya nilai inputan pada sensor LDR tergantung pada terang atau redupnya cahaya yang diterima oleh sensor LDR itu sendiri..[5]

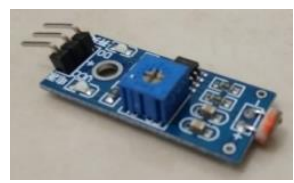

Gbr. 4 Modul LDR

E. Relay

Relay adalah kontaktor saklar yang diaktifkan secara listrik dan merupakan komponen elektromekanikal yang terdiri dari 2 bagian utama yakni Elektromagnet dan Mekanikal. [6]

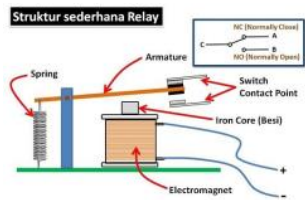

Gbr 5 Struktur Sederhana Relay

\section{F. Sensor Ultrasonik}

Sensor jarak ultrasonik merupakan sebuah sensor yang mampu mendeteksi adanya objek berkisar antara $3 \mathrm{~cm}-3 \mathrm{~m}$. Sensor ultrasonik dapat dilihat pada gambar dibawah ini. Pada umumnya sensor ultrasonic digunakan untuk mendeteksi jarak sesuai dengan kebutuhan sistemnya.

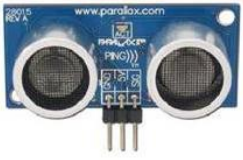

Gbr 6 Ultrasonik

\section{G. Lampu Pijar}

Lampu pijar adalah salah satu jenis lampu yang biasa digunakan dikalangan masyarakat. Kaca yang digunakan untuk menutupi filament panas itu adalah untuk menghalangi udara.

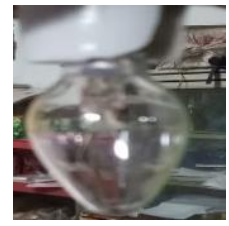

Gbr. 7 Lampu Pijar

\section{H. Flowchart}

Flowchart Sistem merupakan bagan yang menunjukkan alur kerja atau apa yang sedang dikerjakan di dalam sistem secara keseluruhan dan menjelaskan urutan dari prosedur-prosedur yang ada di dalam sistem.

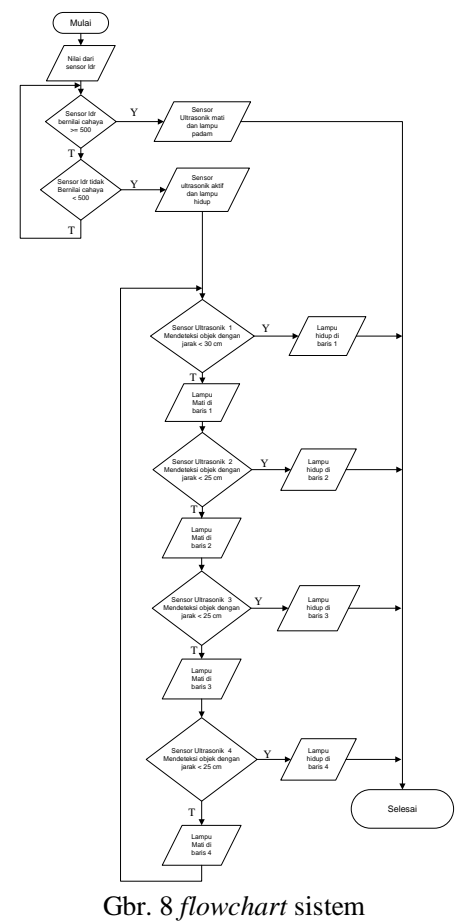


Keterangan gambar flowchart sistem:

1. Mulai,

2. Penginisialisaian Nilai dari sensor ldr,

3. Ketika sensor ldr bernilai < 500 maka sensor ultrasonic akan mati dan lampu padam,

Page|111 4. Ketika sensor ldr bernilai > 500 maka sensor ultrasonic aktif dan lampu akan padam, selanjutnya proses menunggu nilai yang masuk dari sensor ultrasonic untuk mendeteksi jarak,

5. Ketika sensor ultrasonic 1 mendeteksi jarak $<30$ cm maka lampu akan hidup, selanjutnya

6. Ketika sensor ultrasonic 2 mendeteksi jarak $<25$ $\mathrm{cm}$ maka lampu akan hidup, selanjutnya

7. Ketika sensor ultrasonic 3 mendeteksi jarak $<25$ cm maka lampu akan hidup, selanjutnya

8. Ketika sensor ultrasonic 4 mendeteksi jarak $<25$ $\mathrm{cm}$ maka lampu akan hidup, selanjutnya

9. Selesai.

\section{Perancangan Hardware}

Berikut ini adalah perancangan Hardware dari Prototype Penerangan Lampu Taman Otomatis Menggunakan Arduino Uno.

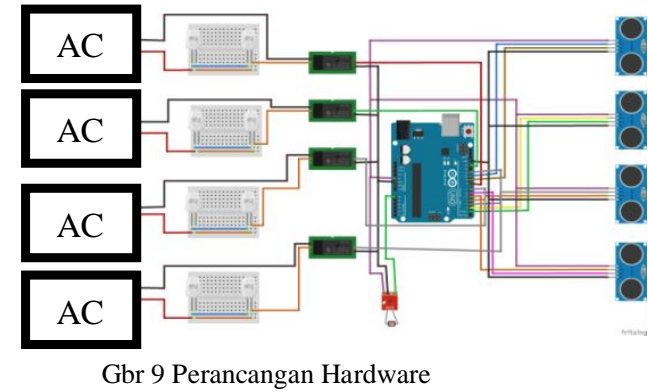

Hubungan dari setiap komponen di atas adalah sebagai berikut:

1. Sensor Ultraasonik 1 ke Arduino Uno

a. Pada pin Vcc di sensor ultrasonic dihubungkan ke pin 5v di arduino,

b. Pada pin Trig di sensor ultrasonic dihubungkan ke pin 10 di arduino,

c. Pada pin Echo di sensor ultrasonic dihubungkan ke pin 9 di arduino,

d. Pada pin Gnd di sensor ultrasonic dihubungkan ke pin Gnd di arduino.

2. Sensor Ultrasonik 2 ke Arduino Uno

a. Pada pin Vcc di sensor ultrasonic dihubungkan ke pin 5v di arduino,

b. Pada pin Trig di sensor ultrasonic dihubungkan ke pin 2 di arduino,

c. Pada pin Echo di sensor ultrasonic dihubungkan ke pin 1 di arduino,

d. Pada pin Gnd di sensor ultrasonic dihubungkan ke pin Gnd di arduino.

3. Sensor Ultrasonik 3 ke Arduino Uno

a. Pada pin Vcc di sensor ultrasonic dihubungkan ke pin 5v di arduino,

b. Pada pin Trig di sensor ultrasonic dihubungkan ke pin 3 di arduino, c. Pada pin Echo di sensor ultrasonic dihubungkan ke pin 4 di arduino,

d. Pada pin Gnd di sensor ultrasonic dihubungkan ke pin Gnd di arduino.

4. Sensor Ultrasonik 4 ke Arduino Uno

a. Pada pin Vcc di sensor ultrasonic dihubungkan ke pin 5v di arduino,

b. Pada pin Trig di sensor ultrasonic dihubungkan ke pin 5 di arduino,

c. Pada pin Echo di sensor ultrasonic dihubungkan ke pin 6 di arduino,

d. Pada pin Gnd di sensor ultrasonic dihubungkan ke pin Gnd di arduino.

5. Sensor Cahaya ke Arduino Uno

a. Pada pin Vec di sensor cahaya dihubungkan ke pin $5 \mathrm{v}$ di arduino,

b. Pada pin A0 di sensor cahaya dihubungkan ke pin A5 di arduino,

c. Pada pin Gnd di sensor cahaya dihubungkan ke pin Gnd di arduino.

6. Relay1 ke Arduino Uno

a. Pada pin IN di relay dihubungkan ke pin 8 di Arduino,

b. Pada pin Vec di relay dihubungkan ke pin $5 \mathrm{v}$ di arduino,

c. Pada pin Gnd di relay dihubungkan ke pin Gnd di arduino.

7. Relay2 ke Arduino Uno

a. Pada pin IN di relay dihubungkan ke pin 13 di Arduino,

b. Pada pin Vec di relay dihubungkan ke pin $5 \mathrm{v}$ di arduino,

c. Pada pin Gnd di relay dihubungkan ke pin Gnd di arduino.

8. Relay3 ke Arduino Uno

a. Pada pin IN di relay dihubungkan ke pin 7 di Arduino,

b. Pada pin Vec di relay dihubungkan ke pin $5 \mathrm{v}$ di arduino,

c. Pada pin Gnd di relay dihubungkan ke pin Gnd di arduino.

9. Relay4 ke Arduino Uno

a. Pada pin IN di relay dihubungkan ke pin 11 di Arduino,

b. Pada pin Vec di relay dihubungkan ke pin $5 \mathrm{v}$ di arduino,

c. Pada pin Gnd di relay dihubungkan ke pin Gnd di arduino.

\section{J. Desain Tampilan Alat}

Desain casing pembuatan Prototype Penerangan Lampu Taman Otomatis Berbasis Arduino Uno ini menggunakan aplikasi sketch Up 2016 dimana pada aplikasi ini dapat menampilkan desain berbentuk 3 dimensi. 


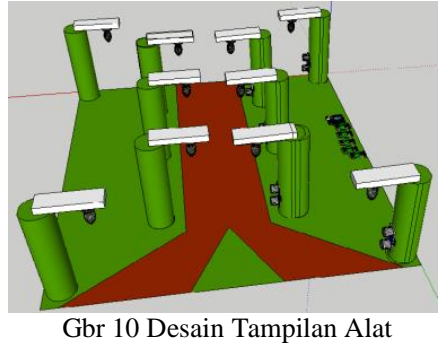

III. KESIMPULAN

Pengujian

Penulis melakukan percobaan dengan memberikan pergerakan, dan disajikan dalam table pengujian dibawah ini:

TABEL I

HASIL PENGUJIAN PROTOTYPE

\begin{tabular}{|c|c|c|c|c|}
\hline $\begin{array}{c}\text { No } \\
\text {. }\end{array}$ & Skenario & $\begin{array}{c}\text { Hasil } \\
\text { yang } \\
\text { diharapk } \\
\text { an }\end{array}$ & $\begin{array}{c}\text { Hasil } \\
\text { Penguji } \\
\text { an }\end{array}$ & $\begin{array}{c}\text { Kesimpul } \\
\text { an }\end{array}$ \\
\hline 1. & $\begin{array}{l}\text { Sensor } \\
\text { Ldr } \\
\text { terkena } \\
\text { cahaya }\end{array}$ & $\begin{array}{l}\text { Sensor } \\
\text { ultrasonik } \\
\text { akan non- } \\
\text { aktif dan } \\
\text { lampu } \\
\text { dalam } \\
\text { keadaan } \\
\text { padam }\end{array}$ & $\begin{array}{l}\text { Sensor } \\
\text { Ultrason } \\
\text { ik akan } \\
\text { non-aktif } \\
\text { dan } \\
\text { lampu } \\
\text { dalam } \\
\text { keadaan } \\
\text { padam }\end{array}$ & Valid \\
\hline 2. & $\begin{array}{l}\text { Sensor } \\
\text { Ldr tidak } \\
\text { terkena } \\
\text { cahaya }\end{array}$ & $\begin{array}{l}\text { Sensor } \\
\text { ultrasonik } \\
\text { akan aktif } \\
\text { dan lampu } \\
\text { dalam } \\
\text { keadaan } \\
\text { padam. }\end{array}$ & $\begin{array}{l}\text { Sensor } \\
\text { Ultrason } \\
\text { ik akan } \\
\text { aktif dan } \\
\text { lampu } \\
\text { dalam } \\
\text { keadaan } \\
\text { padam. }\end{array}$ & Valid \\
\hline 3. & $\begin{array}{l}\text { Sensor } \\
\text { Ultrasoni } \\
\text { k } 1 \\
\text { Meletakk } \\
\text { an objek } \\
\text { di jarak } \\
\text { 30cm }\end{array}$ & $\begin{array}{l}\text { Ketika } \\
\text { objek } \\
\text { terdeteksi } \\
\text { Lampu } \\
\text { akan } \\
\text { hidup, dan } \\
\text { jika sudah } \\
\text { tidak } \\
\text { terdeteksi } \\
\text { lagi maka } \\
\text { lampu } \\
\text { akan } \\
\text { padam }\end{array}$ & $\begin{array}{l}\text { Ketika } \\
\text { terdeteks } \\
\text { i Lampu } \\
\text { akan } \\
\text { hidup, } \\
\text { dan jika } \\
\text { sudah } \\
\text { tidak } \\
\text { terdeteks } \\
\text { i lagi } \\
\text { maka } \\
\text { lampu } \\
\text { akan } \\
\text { padam }\end{array}$ & Valid \\
\hline 4. & $\begin{array}{l}\text { Sensor } \\
\text { Ultrasoni } \\
\text { k } 2 \\
\text { Meletakk } \\
\text { an objek }\end{array}$ & $\begin{array}{l}\text { Ketika } \\
\text { objek } \\
\text { terdeteksi } \\
\text { Lampu } \\
\text { akan } \\
\text { hidup, dan }\end{array}$ & $\begin{array}{l}\text { Ketika } \\
\text { terdeteks } \\
\text { i Lampu } \\
\text { akan } \\
\text { hidup, } \\
\text { dan jika }\end{array}$ & Valid \\
\hline
\end{tabular}

\begin{tabular}{|c|c|c|c|c|}
\hline & $\begin{array}{l}\text { di jarak } \\
25 \mathrm{~cm}\end{array}$ & $\begin{array}{l}\text { jika sudah } \\
\text { tidak } \\
\text { terdeteksi } \\
\text { lagi maka } \\
\text { lampu } \\
\text { akan } \\
\text { padam }\end{array}$ & $\begin{array}{l}\text { sudah } \\
\text { tidak } \\
\text { terdeteks } \\
\text { i lagi } \\
\text { maka } \\
\text { lampu } \\
\text { akan } \\
\text { padam }\end{array}$ & \\
\hline 5. & $\begin{array}{l}\text { Sensor } \\
\text { Ultrasoni } \\
\text { k } 3 \\
\text { Meletakk } \\
\text { an objek } \\
\text { di jarak } \\
25 \mathrm{~cm}\end{array}$ & $\begin{array}{l}\text { Ketika } \\
\text { objek } \\
\text { terdeteksi } \\
\text { Lampu } \\
\text { akan } \\
\text { hidup, dan } \\
\text { jika sudah } \\
\text { tidak } \\
\text { terdeteksi } \\
\text { lagi maka } \\
\text { lampu } \\
\text { akan } \\
\text { padam }\end{array}$ & $\begin{array}{l}\text { Ketika } \\
\text { terdeteks } \\
\text { i Lampu } \\
\text { akan } \\
\text { hidup, } \\
\text { dan jika } \\
\text { sudah } \\
\text { tidak } \\
\text { terdeteks } \\
\text { i lagi } \\
\text { maka } \\
\text { lampu } \\
\text { akan } \\
\text { padam }\end{array}$ & Valid \\
\hline 6. & $\begin{array}{l}\text { Sensor } \\
\text { Ultrasoni } \\
\mathrm{k} 4 \\
\text { Meletakk } \\
\text { an objek } \\
\text { di jarak } \\
25 \mathrm{~cm}\end{array}$ & $\begin{array}{l}\text { Ketika } \\
\text { objek } \\
\text { terdeteksi } \\
\text { Lampu } \\
\text { akan } \\
\text { hidup, dan } \\
\text { jika sudah } \\
\text { tidak } \\
\text { terdeteksi } \\
\text { lagi maka } \\
\text { lampu } \\
\text { akan } \\
\text { padam }\end{array}$ & $\begin{array}{l}\text { Ketika } \\
\text { terdeteks } \\
\text { i Lampu } \\
\text { akan } \\
\text { hidup, } \\
\text { dan jika } \\
\text { sudah } \\
\text { tidak } \\
\text { terdeteks } \\
\text { i lagi } \\
\text { maka } \\
\text { lampu } \\
\text { akan } \\
\text { padam }\end{array}$ & Valid \\
\hline 7. & $\begin{array}{l}\text { Ketika } \\
\text { Sensor } \\
\text { cahaya } \\
\text { Tekena } \\
\text { Cahaya } \\
\text { Terang }\end{array}$ & $\begin{array}{l}\text { Sensor } \\
\text { akan } \\
\text { memberik } \\
\text { an nilai } \\
>500 \\
\text { inputan } \\
\text { untuk } \\
\text { menonakti } \\
\text { fkan } \\
\text { sensor } \\
\text { ultrasonik }\end{array}$ & $\begin{array}{l}\text { Sensor } \\
\text { akan } \\
\text { memberi } \\
\text { kan nilai } \\
>500 \\
\text { inputan } \\
\text { untuk } \\
\text { menonak } \\
\text { tifkan } \\
\text { sensor } \\
\text { ultrasoni } \\
\text { k }\end{array}$ & Valid \\
\hline 8 & $\begin{array}{l}\text { Ketika } \\
\text { Sensor } \\
\text { cahaya } \\
\text { Tekena } \\
\text { Cahaya } \\
\text { Terang }\end{array}$ & $\begin{array}{l}\text { Sensor } \\
\text { akan } \\
\text { memberik } \\
\text { an nilai } \\
<500 \\
\text { inputan } \\
\text { untuk } \\
\text { mengaktif } \\
\text { kan sensor } \\
\text { ultrasonik }\end{array}$ & $\begin{array}{l}\text { Sensor } \\
\text { akan } \\
\text { memberi } \\
\text { kan nilai } \\
<500 \\
\text { inputan } \\
\text { untuk } \\
\text { mengakt } \\
\text { ifkan } \\
\text { sensor }\end{array}$ & Valid \\
\hline
\end{tabular}




\begin{tabular}{|c|c|c|c|c|c|}
\hline & & & & $\begin{array}{l}\text { ultrasoni } \\
\mathrm{k}\end{array}$ & \\
\hline Page | 113 & 9. & $\begin{array}{l}\text { Ketika } \\
\text { Sensor } \\
\text { ultrasonik } \\
1 \\
\text { mendetek } \\
\text { si objek } \\
\text { dengan } \\
\text { jarak } \\
\text { tidak } \\
\text { lebih dari } \\
30 \mathrm{~cm}\end{array}$ & $\begin{array}{l}\text { Ketika } \\
\text { terdeteksi } \\
\text { objek } \\
\text { dengan } \\
\text { jarak } \\
\text { dibawah } \\
\text { 30cm } \\
\text { maka } \\
\text { lampu } \\
\text { akan } \\
\text { hidup, dan } \\
\text { jika tidak } \\
\text { terdeteksi } \\
\text { lagi maka } \\
\text { lampu } \\
\text { akan mati }\end{array}$ & $\begin{array}{l}\text { Ketika } \\
\text { terdeteks } \\
\text { i objek } \\
\text { dengan } \\
\text { jarak } \\
\text { dibawah } \\
\text { 30cm } \\
\text { maka } \\
\text { lampu } \\
\text { akan } \\
\text { hidup, } \\
\text { dan jika } \\
\text { tidak } \\
\text { terdeteks } \\
\text { i lagi } \\
\text { maka } \\
\text { lampu } \\
\text { akan } \\
\text { mati }\end{array}$ & Valid \\
\hline & 10. & $\begin{array}{l}\text { Ketika } \\
\text { Sensor } \\
\text { ultrasonik } \\
1 \\
\text { mendetek } \\
\text { si objek } \\
\text { dengan } \\
\text { jarak } \\
\text { tidak } \\
\text { lebih dari } \\
25 \mathrm{~cm}\end{array}$ & 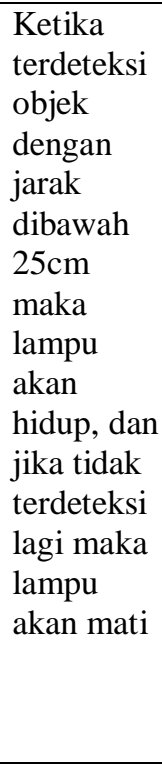 & $\begin{array}{l}\text { Ketika } \\
\text { terdeteks } \\
\text { i objek } \\
\text { dengan } \\
\text { jarak } \\
\text { dibawah } \\
25 \mathrm{~cm} \\
\text { maka } \\
\text { lampu } \\
\text { akan } \\
\text { hidup, } \\
\text { dan jika } \\
\text { tidak } \\
\text { terdeteks } \\
\text { i lagi } \\
\text { maka } \\
\text { lampu } \\
\text { akan } \\
\text { mati }\end{array}$ & Valid \\
\hline
\end{tabular}

\section{A. Simpulan}

Berdasarkan hasil pengujian di atas, maka didapatlah beberapa informasi:

1. Peneliti menggunakan Arduino ide dengan menggunakan sensor LDR dan Ultrasonic yang telah selesai di laksanakan dan berhasil di implementasikan.

2. Penggunaan ultrasonic dan $\mathrm{ldr}$ digunakan untuk mengukur jarak dalam mengaktifkan lampu otomatis.

3. Penggunaan sensor ultrasonic dan sensor ldr dapat digunakan sebagai penghias dan mempercantik taman.
4. Pengujian ini menggunakan aliran arus ac sebagai penambah daya listrik yang akan benar benar menghasilkan tampilan real.

B. Saran

Adapun saran yang dapat peneliti sampaikan pada akhir tugas akhir ini adalah sebagai berikut :

1. Peneliti juga berharap agar dapat mengembangkan dari hasil yang peneliti buat menjadi lebih baik lagi

2. Untuk tingkat dalam pengembangan baik dari dalam kampus sendiri maupun dari kampus luar, peneliti berharap agar dapat mengembangkan alat ini sebaik mungkin dengan menggunakan sensorsensor yang lebih bagus atau dapat mengimplementasikan dengan real dan lebih bermanfaat untuk orang banyak, serta dapat menggunakan mikrokontroler yang dapat menggunakan internet of things seperti ESP8266, RASPBERRY PI, WEMOS D1, ESP32 dan sebagainya.

\section{REFERENS}

[1] Parhan, J., \& Rasyid, R. (2018). Rancang Bangun Sistem Kontrol Kipas Angin dan Lampu Otomatis di Dalam Ruang Berbasis Arduino Uno R3 Menggunakan Multisensor, 7(2), 159-165.

[2] Eddi, Suhery, C., \& Triyanto, D. (2013). Sistem Penerangan Rumah Otomatis Dengan Sensor Cahaya Berbasis Mikrokontroler. Jurnal Coding Sistem Komputer Universitas Tanjungpura, 1(2), 1-10.

[3] Tsauqi, A. K., Manuel, I., Hasan, V. M., Tsalsabila, A., Chandra, F., Yuliana, T., \& Tarigan, P. (2016). Saklar Otomatis Berbasis Light Dependent Resistor ( LDR ). $L d r$, $V$ (Seminar Nasional Fisika SNF2016), 19-24. https://doi.org/doi.org/10.21009/0305020105

[4] R. Aulia and A. J. Lubis, "Monitoring Suhu udara Kawasan Gunung Aktif berbasis IoT," Jurnal Teknologi dan Ilmu Komputer Prima, vol. 1, no. April 2018, pp. 115-122, 2019.

[5] Albet, M., Ginta, P. W., \& Sudarsono, A. (2014). Pembuatan Jendela Otomatis Menggunakan Sensor Cahaya. Jurnal Media Infotama, 10(1), 8-15.

[6] K, V. D., \& Syaryadhi, M. (2017). Monitoring Suhu dan Kelembaban Menggunakan Mikrokontroler ATMega328 pada Proses Dekomposisi Pupuk Kompos, 2(3), 91-98. 